JOALL (JOURNAL OF APPIIED LINGUIS'IICS ANI) LITIERA'TURE)

Vol. 4 No. 2, 2019

ISSN (print): 2502-7816; ISSN (online): 2503-524X

Available online at https:/ / ejournal.unib.ac.id/index.php/joall/index doi: http://dx.doi.org/10.33369/joall.v4i2.7681

\title{
SYNTACTICAL ERROR ANALYSIS ON REPORT TEXT
}

\author{
Soraya Grabiella Dinamika'; Ridwan Hanafiah² \\ Sekolah Tinggi Ilmu Manajemen Sukma Medan" Universitas Sumatera Utara² \\ Corresponding email: dinamika.soraya@gmail.com
}

\begin{abstract}
This study aims at investigating and classifying the syntactical errors in the writing of report text made by 20 students of Department of English Literature of FIB-USU. Syntactical errors in writing made by EFL students are needed to be investigated by using the Error Analysis theory developed by Gass \& Selinker in 2008 as it provides six appropriate investigation procedures, namely; collecting data, identifying errors, classifying errors, quantifying errors, analyzing errors and remediation. Each of students was assigned to write a topicbased report text with the length of 150 up to 250 words in count. This study dealt with a qualitative descriptive approach. After the EA procedures applied, in this study found that the students made major syntactical errors within the use of article 'a/an',' the' in terms of omission and addition of articles, the use of relative pronoun, and the use of subject-verb agreement in terms of past tense agreement and number agreement. Based on the error analysis procedure applied, it was obtained that the most predominant syntactical errors made by the students was the use of article which comprises of 125 errors (50.2\%), followed by the use of subject-verb agreement with 117 errors (47\%) and followed by the use of relative pronoun as the least error which comprises of 7 errors $(2.8 \%)$. The syntactical error made by the students caused by two major sources, intra-language error and intra-language error. By seeing at these problematic areas, the researcher has suggested to take out several related pedagogical remediation to the students.
\end{abstract}

Keywords: report text writing, syntactical error, error analysis, pedagogical remediation

\section{INTRODUCTION}

There are several numbers of English texts that should be mastered by the students; one of the notable is the report text. Gerot \& Wignell (1994:196) define report text as a genre of text which aims to describe the way things are, with reference to a range of natural, man-made and social phenomenon in our environment. Report text may reveal the natural phenomenon such as 
living or non-living things, and social phenomenon such as technology, economic issue, parliament, and political parties. Since report text is a common text taught to students of English major, therefore it has been assumed that the students are familiar with it, in terms of the use of its grammatical features and generic structures. Yet, though the fact appears to be so, the errors in writing are still found in non-English speaking students' writing productions.

In learning L2, errors are common to happen. There are factors causing it, for instance that L2 may have different language grammar with L1, the lack of students' knowledge about L2 structure, misperception, language misuse and interference. But, in fact, the errors are often ignored by the teacher as the guide in learning. Therefore the students don't have idea about the errors they make. They don't receive any uptakes and feedbacks in their writing production, while it is essential for their writing skill. Error refers to the systematic errors of the learner from which are able to reconstruct his knowledge of the target language. It reflects a portion of the learner's competence in the target language. Thus, error cannot be selfcorrected. Corder (1981:24) claims that the making of errors is significant because it is part of the learning process itself. He also adds that the process of learning a second language is a fundamentally different nature from the process of primary acquisition. In order to get the uptake and feedback on their writing, it is needed to have a further analysis toward the errors students make. Therefore, in order to analyze errors made by the learners, some experts in second language acquisition field then construct an approach namely, Error Analysis (EA).

Gass \& Selinker (2008:103) define EA as a procedure for analyzing second language data that begins with the errors learners make and then attempts to explain them. According to them, there are two main sources of error, namely inter-language (negative interference from L1) and intralanguage (developmental errors between L1 and L2). Error analysis has successfully proven its function in analyzing L2 learners' errors in numerous research of classroom situation. By seeing at the success of EA procedures conducted in L2 classroom situation, it is necessary for the researcher to take an insight over several previous researches on this field.

Research on error analysis has been frequently done. Thus, it is important to take a view on former ones. Zawahreh (2012) investigated the written English errors of 350 tenth grade students in females and males schools in Ajloun, Jordan. The students were asked to write a free essay about "A journey to the ancient city of Jerash in Jordan" in an ordinary English language exercise in the class. The findings were respectively; the most predominant errors among tenth grade students in Ajloun schools within morphology errors of lack of agreement between subject and the 
main verb, function words errors of insertion of prepositions, syntax errors of omission of the main verb, tenses errors of using present instead of past, and lexical items errors of lexical item order.

Barzegar (2013) committed to analyzing Persian Learners of English made in converting ten Persian sentences into English. The data of the research was analyzed according to several procedures, such as collecting, describing, analyzing and evaluating the errors that were made by the intermediate level students from the Simin Institute in Ramsar, Iran. The result of the study indicate that the majority of errors produced by these learners involve syntactic morphological errors in the descriptive of errors, substitution in the process of errors, and intralingua errors dominated the source of errors.

Those previous researches took places in Middle East countries which known as non-English speaking countries just like Indonesia, but, the similar research hardly nationally ever done in Indonesia and North Sumatera Province, locally. Since the Indonesian language and English language have different language structure, thus the errors occur may differ in some ways as well. Therefore, research on syntactical errors is immediately necessary to do in this local area, for avoiding Indonesian students from making another error by going through the factors causing it.

This research answers its necessity by analyzing the syntactical errors made by students of Department of English Literature of FIB-USU, in their English report text writing. The students have been exposed to English language and structure since they were in the first semester. Since being the English students requires them to be able to use English both in written and oral register, therefore they are expected that making error sentences is none of their problem any longer. Thus, this research aims at investigating whether the students make any syntactical errors. If any, the researcher intends to classify the type of errors and explain the source of errors as well. Furthermore, to define errors made by the students, contrasting L1 and L2 grammar is undertaken. Moreover, error analysis is expected to give some useful pedagogical remediation for the students to avoid making another syntactical error in their writings in the future. The objectives of this study are to; (1) find out the most predominant errors made by the students, (2) investigate the source causing the errors, and (3) take out pedagogical remediation that suits the syntactical errors found.

\section{METHODS}

This research engaged with qualitative descriptive approach. In this research, to analyze the student's syntactical error, only the student whose L1 is Indonesian and L2 is English taken as the data source. Besides, in order to analyze the source of errors in English students' report text writings, the 
researcher applies the Error Analysis approach designed by Gass \& Selinker in 2008, for it provides complete procedures of EA, namely collecting data, identifying errors, classifying errors, quantifying errors, analyzing errors and remediation; it is appropriate to be applied in the typical of classroom second language research; and it provides the analysis with the causing factors called inter-language and intra-language errors.

\section{Participants}

There were 20 undergraduate students of English Literature Department of FIB-USU, class of Regular A \& B in the academic year of 2015/2016 involved in this research. They were at the sixth semester and had passed the subject of writing I-IV and English structure I-IV as well. They were assumed that they had achieved whole Basic English grammatical skills. Moreover, these students were going to continue writing their final thesis to reach a bachelor degree, in which the final thesis generally in the form of report text. Thus, the researcher took them as the participants.

\section{Instruments}

The participants were assigned to write a topic-based report text on Indonesian General Election 2014. The researcher defined the length of the writing as 150 up to 250 words in count. The writing sheet were distributed to the students, afterwards the writing sheets were collected as the data source of this study.

\section{Procedures}

There were six EA procedures applied in this study to analyze the data, respectively named; (1) collecting data, (2) identifying errors,(3) classifying errors, (4) quantifying errors, (5) analyzing errors and (6) remediation.

At first, the data are analyzed based on each student's writing result. Next, the errors found categorized into its type of errors. The analysis is tabulated to make it easier to be read. Then, the researchers expose the error form by italicizing it, in order to distinguish it with the correct form. Afterward the error is quantified to know its frequency of occurrence. Then, the errors are analyzed due to its source of error, whether inter-language error of intra-language error. Moreover, this type of tabulated analysis is applied to the entire 20 students' writing results. As the last procedure of error analysis, the pedagogical remediation is intended to be carried out to the students based on problematic area in syntactical errors.

\section{FINDINGS}

The 20 students' writing sheets were respectively analyzed due to six procedures of EA. After all of the data had been analyzed thoroughly, then it 
came to several findings. The typical syntactical errors found in the students' writing sheets were mostly the use of article in terms of omission and addition of articles, the use of relative pronoun, and the use of subject-verb agreement in terms of past tense agreement and number agreement. The result of analysis is presented as followings;

The Use of Article 'a/an',' the'

The first error being analysed was the use of English article, namely 'a/an',' the'. The use of article was then subcategorized in two subs; omission and addition. On the table 1 below, the brief view of analyzed error is presented.

Table 1: The use of article error

\begin{tabular}{|c|c|c|c|c|c|}
\hline No & Initial & Type of Errors & Error Form & $\begin{array}{c}\text { Frequency } \\
\text { of } \\
\text { Occurrence }\end{array}$ & $\begin{array}{l}\text { Source \& } \\
\text { Cause }\end{array}$ \\
\hline \multirow[t]{5}{*}{1} & \multirow[t]{5}{*}{$\mathrm{APP}$} & The use of article & & & \\
\hline & & Omission of 'a/an' & - & - & - \\
\hline & & \multirow[t]{2}{*}{ Omission of 'the' } & $\begin{array}{l}\text {...their logo } \\
\text { which called Red } \\
\text { Garuda }^{1}\end{array}$ & \multirow[t]{2}{*}{2} & $\begin{array}{l}\text { Intra-language } \\
\text { error }\end{array}$ \\
\hline & & & $\begin{array}{l}\ldots K P U^{1} \text { officially } \\
\text { announced ... }\end{array}$ & & $\begin{array}{l}\text { Intra-language } \\
\text { error }\end{array}$ \\
\hline & & Addition of 'a/ $\mathrm{an}^{\prime}$ & - & - & - \\
\hline
\end{tabular}

On the brief example above, it was found that the student still made errors in using article 'the'. The proper noun should be preceded by article 'the', as in Red Garuda and KPU for they belong to definite noun. Meanwhile, the students omitted using article 'the', it reflects his inability in using L2 structure or called intra-language error.

After all data analyzed, then the final quantification was made to gather the results of article error. Then it was found that article errors occurred for 125 times with 125 intra-language error source.

\section{The Use of Relative Pronoun}

The second errors being analyzed was the use of relative pronoun, which was projected to the use of relative pronoun unit, such as; who, whom, which, whose, that. The table 2 below is presented to show the show the example of clause error made by the student.

Table 2: The use of relative pronoun error

\begin{tabular}{ccccc} 
No & $\begin{array}{c}\text { Student's } \\
\text { Initial }\end{array}$ & $\begin{array}{c}\text { Type of } \\
\text { Errors }\end{array}$ & Error Form & $\begin{array}{c}\text { Frequency } \\
\text { of } \\
\text { Occurrence }\end{array}$ \\
Source \& Cause \\
\hline
\end{tabular}




\begin{tabular}{cccccc}
\hline No & $\begin{array}{c}\text { Student's } \\
\text { Initial }\end{array}$ & $\begin{array}{c}\text { Type of } \\
\text { Errors }\end{array}$ & \multicolumn{1}{c}{ Error Form } & $\begin{array}{c}\text { Frequency } \\
\text { of } \\
\text { Occurrence }\end{array}$ & Source \& Cause \\
\hline APP & $\begin{array}{l}\text { The use of } \\
\text { relative } \\
\text { pronoun }\end{array}$ & $\begin{array}{l}\text { The party } w h 0^{1} \text { receive } \\
\text { 25\% of national vote, } \\
\text { was out of number. }\end{array}$ & 1 & $\begin{array}{l}\text { Intralanguage } \\
\text { error }\end{array}$ \\
\hline
\end{tabular}

From the example above, it could be seen that the student wasn't able to use the proper relative pronoun unit. For a name of an organization, he put 'who' instead of 'which/ that'. It shows that he found it difficult to distinguish the subject preceding the relative unit.

After all data analysed, the final quantification was made to figure out the total number of the use of relative pronoun error. Thus, it was obtained that relative pronoun errors donated seven occurrences with 1 inter-language source and 6 intra-language sources.

\section{The Use of Subject- Verb Agreement}

The last syntactical error categories being analysed was the use of subjectverb agreement (SVA). The SVA analysis then subcategorized into two; the use of number and the use of tenses. Table 3 below is presented to project the example of error found in the clause.

Table 3: The use of SVA error

\begin{tabular}{|c|c|c|c|c|c|}
\hline No & $\begin{array}{l}\text { Student's } \\
\text { Initial }\end{array}$ & $\begin{array}{l}\text { Type of } \\
\text { Errors }\end{array}$ & Error Form & $\begin{array}{l}\text { Frequency } \\
\text { of } \\
\text { Occurrence }\end{array}$ & Source \& Cause \\
\hline \multirow[t]{5}{*}{1} & APP & $\begin{array}{l}\text { The use of } \\
\text { number } \\
\text { agreement }\end{array}$ & $\begin{array}{l}\text { Even though there } \\
\text { were several } \\
\text { miscommunication }{ }^{1}\end{array}$ & 1 & $\begin{array}{l}\text { Intralanguage } \\
\text { error }\end{array}$ \\
\hline & & \multirow{4}{*}{$\begin{array}{l}\text { The use of } \\
\text { tense } \\
\text { agreement }\end{array}$} & $\begin{array}{l}\text { The party who receive } \\
25 \% \text { of national vote, } \\
\text { was out of number. }\end{array}$ & \multirow{4}{*}{4} & \multirow{4}{*}{$\begin{array}{l}\text { Intralanguage } \\
\text { error } 1,2,3,4\end{array}$} \\
\hline & & & $\begin{array}{l}\text { As the former parties } \\
\text { which hold }{ }^{2} \text { the flag } \\
\text { were PDI-P and } \\
\text { Gerindra }\end{array}$ & & \\
\hline & & & $\begin{array}{l}\text { Jokowi and Jusuf Kalla } \\
\text { take }^{3} \text { the responsibility } \\
\text { of the election }\end{array}$ & & \\
\hline & & & $\begin{array}{l}\text { The KPU announced } \\
\text { both of them, govern } \\
\text { Indonesia legally... }\end{array}$ & & \\
\hline
\end{tabular}

The student on the example above made several errors in using subject-verb agreement. In terms of number agreement, he couldn't deal the auxiliary 'were' and quantifier 'several' with the noun 'miscommunication', 
which was supposed to be parallel with its former class of words, it needed to be 'miscommunications'. Whilst in the use of tense agreement the student made errors in selecting the verbs. In fact, the report text he made happened in the past few years, in which verb type II (past tense) needed to be used. It showed that the student still had problem in using L2 structure or called intra-language error. Therefore, the verb 'receive' should be 'received', the word 'hold' should be 'held', the word 'take' should be 'took', and the word 'govern' should be 'governed'.

After all data of SVA analysed, the final quantification was obtained as followings; SVA errors occurred for 117 in total, with description of 22 number agreement errors and 95 tense agreement error. While interlanguage errors occurred for 9 times and 108 intra-language errors.

At last, the syntactical errors made by the students in 20 report texts came to 249 errors in total. In which respectively construed for 10 interlanguage errors and 239 intra-language errors.

\section{DISCUSSION}

The errors found in this analysis might have caused by several factors. The most logical one is that the students' L1 is Indonesian language while English language is foreign to them. Those findings are further presented in discussion section below.

The use of article errors was sub-categorized into type of article whether addition or omission. The omission of 'a/an' occurs for 9 times, which entirely caused by the intra-language error. The omission of 'the' occurred for 69 times, which entirely caused by the intra-language errors. Meanwhile, the addition of 'a/an' occurred for 10 times, and the addition of 'the' occurred for 37 times, then the additions of article were entirely caused by intra-language error as well. These results showed that the students hadn't completely mastered using the article in English language. No interference from L1 in this type of syntactical error happened for there is no function of article use in Indonesian language just like what English language has.

Table 2 showed that the use of relative pronouns errors occurred only 7 times. The errors mostly caused by 6 intra-language error and 1 interlanguage error. This was the least syntactical errors occurred, because the students wrote lesser relative clauses than other clauses. Yet, writing English relative clauses was demanded to be practiced more by the students, since there is only relative pronoun unit in Indonesian language, namely "yang", while the English has five, namely who, which, whose, whom and that.

Table 3 showed that the use of subject verb agreement (SVA) occurred for 117 times. It was constituted by the use of number agreement and the use of past tense agreement. The number of agreement errors occurred for 22 
times which caused by 3 inter-language errors and 19 intra-language errors. Meanwhile, the tense agreement errors occurred for 95 times which caused by 6 inter-language errors and 89 intra-language errors. It was obviously a huge number of errors found in 20 students' writing results. Differences in structure of Indonesian language and English language might have been causing the occurrences of SVA errors. In Indonesian language structure, change of tenses doesn't exist, so there are no verb or predicate changes. Moreover, number of subject doesn't affect the changes of verb.

Eventually, in relation to the objective of the study, it was found that the most predominant syntactical errors fell into the use of article, followed by the use of SVA and the use of relative pronoun respectively. The most influencing errors caused by the intra-language source (L2 interference). Clearly, by seeing through these findings, some pedagogical remediation related to syntactical and English grammatical needed to be carried out.

\section{Remediation}

The remediation is carried out to be the step of overcoming the findings of this study, therefore errors can be avoided in the future study. This step can be beneficial for; the students as the language learner; the teacher as the classroom learning mediator and facilitator; the course and syllabus designer; and the other researcher who work in language field.

Firstly, in relation to the results of article use error analysis, it is suggested for the students to learn more about the function of article in sentence. Therefore the students need to understand when they need to omit the unnecessary article, and in what condition they need to add a necessary article, or even when to use no article at all. Reading more about the theory of English article and part of speech may improve students' knowledge. Practicing more to write or read about English text stories, poems, movie scripts, songs and any other printed mediums may challenge students to be more aware on article errors. The teacher may provide them with more complete medium of learning and exact method to teach article.

Secondly, due to the errors of relative pronoun, the students are required to have more understanding in using the relative pronoun relator. They have to learn to use the relative pronoun in different type of clause, for each relative pronoun relator has each own function in different clause context. The teacher may ask the students to do some practice in using relative pronoun relator directly when the students want to say two or more clauses at one time, so they could avoid redundancy in using clauses.

Thirdly, on the error of SVA use, the students need to be consistent on the tenses form being used. For instance, when a student writes a text composition by using past tense form, apparently the next sentence fragment should be written by using past tense form as well. However, learn 
more about the use SVA can be started from memorizing verb changes such as Verb Type I, II, and III. Then, they may go one step further to use it in daily conversation or task. They also need to practice it in writing sections. Facing this kind of error, it is suggested to the teacher to give facilitations and proper medium for learning SVA, such as giving the proper course design and upgrading the method of teaching SVA. By applying this consistency, hopefully, can help students to avoid making tense agreement errors. The number agreement errors can be avoided if the students completely understand about the verb changing form depending on the singular or plural subject. Thus, it is suggested that the students work more on the understanding of number agreement and focus on the number case of subject. Due to the findings that the error is caused mostly by intralanguage errors, thus, the students are required to be even more serious in learning and practicing English grammar, whether in writing or speaking skill. In addition, the researcher recommends the students to keep reading books which related to English grammar and genre-based writing.

\section{CONCLUSION AND SUGGESTION}

Based on the error analysis applied, it is concluded that the 20 students of Department of English Literature of FIB-USU still make syntactical errors in their report text writing results. The results appeared to be; the use of article is the most predominant errors which comprises of 125 errors (50.2\%), followed by the use of subject-verb agreement with 117 errors (47\%) and followed by the use of relative pronoun as the least error which comprises of 7 errors $(2.8 \%)$. In relation with the analysis of source of errors, the intralanguage error causes the most errors with account of 239 times of occurrences, while the inter-language error occurs for 10 times. This finding shows that the students cannot completely master and apply the grammar of English in terms of syntactical function into their writing. In line with the result of analysis, the researcher has carried out several pedagogical remediations for the students based on problematic area of syntactical error.

Analyzing error is a field that might develop day by day according to the type participants, degree of education, language skill, source and target of language and any other influencing factors, moreover, the further studies on error analysis needs to be administered within different aspects, whether it is still in the field of language either in the field of its grammatical structure. Therefore, analysis on error may go beyond the morphological aspects or even beyond the clause and discourse ones. This study is supposed to be references for another researcher, linguist and educator, for their further study on error analysis. 


\section{REFERENCES}

Barzegar, M. (2013). Persian EFL Students' Error Analysis. Asian Journal Of Social Sciences \& Humanities. Volume 2 (No. 4: 2013): 322-334.

Corder, S.P. 1981.Error Analysis and Interlanguage. Oxford: Oxford University Press.

Dinamika, S.G. (2016). Report text on Indonesian general election 2014: a grammatical error analysis. [Unpublished Thesis]. Medan: University of Sumatera Utara, Postgraduate Program.

Frank, M. (1972). Modern English: A Practical Reference Guide. New Jersey: Prentice-Hall, Inc.

Gass, S.M. and Selinker, L. (2008). Second Language Acquisition: An Introductory Course. New York: Routledge Taylor and Francis Group.

Gerot, L. and Wignell, P. (1994). Making Sense of Functional Grammar. Sydney: Southwood Press.

Greenbaum, S. and Nelson, G. (2002). An Introduction to English Grammar. London: Pearson Education Limited.

Kroeger, P.R. (2005). Analyzing Grammar: An Introduction. Cambridge: Cambridge University Press.

Lado, R. (1957). Linguistics Across Cultures. Ann Arbor: University of Michigan Press.

Richards, J.C, ed. (1972). Error Analysis: Perspective on Second Language Acquisition. New York: Longman.

Zawahreh, F.A.E. (2012). Applied Error Analysis of Written Production of English Essays of Tenth Grade Students in Aljoun Schools, Jordan.International Journal of Learning \& Development.Volume 2 (No. 2:2012): 280-299. 